\title{
Effect of Vitamin C on mortality of critically ill patients with severe pneumonia in intensive care unit: A preliminary study
}

\section{Ata Mahmoodpoor}

Tabriz University of Medical Sciences

\section{Kamran Shadvar}

Tabriz University of Medical Sciences

\section{Sarvin Sanaie}

Tabriz University of Medical Sciences

\section{Mir Reza Hadipoor}

Tabriz University of Medical Sciences

Mohammad Ata Pourmoghaddam

Yeditepe Universitesi Dis Hekimligi Fakultesi

seied hadi saghaleini ( $\sim$ hsaghaleini@gmail.com )

Tabriz University of Medical Sciences https://orcid.org/0000-0003-4996-4372

\section{Research article}

Keywords: Vitamin C, pneumonia, mortality, critically ill

Posted Date: January 21st, 2021

DOI: https://doi.org/10.21203/rs.3.rs-46003/v3

License: (1) This work is licensed under a Creative Commons Attribution 4.0 International License. Read Full License 


\section{Abstract}

Background: Critically ill patients frequently suffer from vitamin C deficiency. Previous studies showed that

high doses of vitamin $\mathrm{C}$ administration had conflicting results on clinical outcomes in patients with severe sepsis, burns and trauma. Because of the high incidence and morbidity/mortality with severe pneumonia, we aimed to investigate the effect of administration of high dose vitamin $\mathrm{C}$ in critically ill patients with severe pneumonia.

Methods: Eighty critically ill patients with pneumonia were enrolled in this randomized double blinded clinical trial. Patients with CURB-65 score $>3$, one major criteria, or $\geq 3$ minor criteria were considered as severe pneumonia. Patients were randomly assigned to intervention or placebo groups receiving standard treatment plus $60 \mathrm{mg} / \mathrm{kg} /$ day vitamin $\mathrm{C}$ as continuous infusion or normal saline in the same volume correspondingly for 96 hours. Serum levels of vitamin $\mathrm{C}$ were noted at baseline and 48 hours after vitamin $\mathrm{C}$ administration. Duration of mechanical ventilation, ICU length of stay, $\mathrm{PaO} 2$ /FiO 2 and mortality rate were noted for all patients till the 28 th day. Any complications related to the vitamin $\mathrm{C}$ administration were recorded. (IRCT registration number: IRCT20190312043030N1 , Registration date: 2019-08-26, seied hadi saghaleini).

Results: Duration of mechanical ventilation and vasopressor use were significantly lower in intervention group ( $p:<0.001$ and 0.003 , respectively). Baseline levels of vitamin $C$ in both groups did not have significant difference but its levels increased in intervention group and decreased in control group during the study period. Mortality rate insignificantly decreased in intervention group ( $p: 0.17)$. Three patients showed hypotension and tachycardia during the administration of vitamin $\mathrm{C}$ which was self-limited with decreasing the dose of vitamin $\mathrm{C}$.

Conclusion: Our results showed that the intravenous administration of a relatively high dose of vitamin $\mathrm{C}$ to critically ill patients with severe pneumonia was safe and could decrease the inflammation, duration of mechanical ventilation and vasopressor use without any significant effect on mortality ( $P$ value: 0.17 ).

\section{Background}

Plasma levels of vitamin C are usually decreased in the critically ill patients with sepsis, burn, major surgeries, trauma and any disease accompanied with immune dysfunction and inflammation ${ }^{1}$. This reduction in Vitamin $\mathrm{C}$ level is contributed to lower intake and higher metabolism in critically ill patients ${ }^{2}$. Based on the modulation of oxidative stress, endothelial protection, and involvement in organ's functionality and energy metabolism, vitamin $\mathrm{C}$ represents an interesting therapeutic approach in critically ill patients as a safe and low-cost nutrient. Recently, there are many published trials about the positive effect of combination therapy of high dose vitamin C, thiamin and fludrocortisone in septic patients. They showed that this combination which targeted multiple components of host response could synergistically restore the immune dysfunction; however, future studies showed different results regarding morbidity and mortality ${ }^{3,4}$. Based on the high incidence of pneumonia in critically ill patients and its effect on mortality, it seems that the effects of vitamin C on respiratory infections are also important at the level of fundamental 
concepts. Corkovic et al. showed that the serum level of vitamin C significantly decreased in patients with acute pneumonia and patients with exacerbation of COPD. They also showed a negative correlation between level of vitamin $\mathrm{C}$ and laboratory markers of inflammation ${ }^{5}$. Results of a systematic review in 2004 showed that vitamin C substantially reduced the incidence or severity of respiratory infections but there were many questions about heterogeneity of trials, route and dose of vitamin $\mathrm{C}$ administration, and sample size of the studies ${ }^{6}$. Results of a recently published Cochrane systematic review showed skepticism about the effect of vitamin $\mathrm{C}$ supplementation for prevention and treatment of pneumonia. They also emphasized to conduct better-quality studies for assessment of the role of vitamin C supplementation in the prevention and treatment of pneumonia ${ }^{7}$. Considering the dosing and route of administration is a very important issue in vitamin C therapy of critically ill patients. It is unclear whether the dosing strategy should attempt to achieve normal or supraphysiologic plasma vitamin $\mathrm{C}$ levels. On the other hand, intravenous dose is necessary and enteral uptake due to gut dysfunction is unpredicted ${ }^{8}$. Recent trials showed that high dose vitamin C (2-3 g/day) is recommended to restore normal plasma concentration ${ }^{9,10}$. Studies which used high doses of vitamin C (3-10 g/day) showed advantageous effects on biological and clinical outcome in critically ill patients ${ }^{11,12}$. Based on the safety profile and molecular characteristics of vitamin $\mathrm{C}$ in critically ill patients and controversial results of the previous studies, we aimed to evaluate the effect of high dose intravenous administration of vitamin C on mortality of critically ill patients.

\section{Methods}

After obtaining ethics committee approval and getting informed consent from patients or their legal guardian (when the level of consciousness of patients was low), 80 critically ill patients with severe pneumonia were enrolled in this randomized double blinded clinical trial. (Trial registration number: IRCT, 20190312043030N1).

All patients who were admitted to intensive care unit (ICU) of a university-affiliated hospital in northwest of Iran with the diagnosis of severe pneumonia were enrolled in this study from May 2019 till Dec 2019. Patients with CURB- 65 score $>3$, one major criteria, or $\geq 3$ minor criteria were considered as severe pneumonia. Exclusion criteria were age less than 18 and more than 80 years old, renal insufficiency, history of vitamin C usage during past 48 hours, allergy to vitamin C, pregnancy or breastfeeding, life expectancy of less than 24 hours, previously complicated with end-stage lung disease, end-stage malignancy, glucose6-phosphate dehydrogenase deficiency, diabetic ketoacidosis, active kidney stone disease, and participation in another clinical trial at the same time. Severity of pneumonia was diagnosed based on CURB-65 (confusion, uremia, respiratory rate, BP, and age $\geq 65$ years) and PSI index.

We constructed 6 blocks in AABB, BBAA, ABAB, BABA, ABBA and BAAB using four blocks. We assigned 1 to 6 for each block. Then, using the random number table, based on the sample size, 20 units of 4 blocks was selected so that we considered having 40 people in control group and 40 people in intervention group. Therefore, we did block randomization. In this study, patients, clinical caregivers, and data analyzers were not aware of grouping. Patients were randomly assigned to one of the following groups: intervention group 
in which patients received standard treatment plus $60 \mathrm{mg} / \mathrm{kg} /$ day vitamin C as continuous infusion for 96 hours. Patients in control group received standard treatment plus intravenous infusion of normal saline as the placebo in the same volume. Standard pneumonia therapy included of empirical antibiotic therapy before the administration of appropriate antibiotic based on the bacteria isolated on laboratory testing, as well as adjunct respiratory therapy. Patients' demographic characteristics were recorded during the study period. Sequential organ failure assessment (SOFA) was assessed during the study and acute physiologic and chronic health evaluation (APACHEII) was assessed on the first day of ICU admission. We evaluated patients for any complication during intravenous infusion of vitamin $\mathrm{C}$ including hypotension (systolic blood pressure less than $70 \mathrm{mmHg}$ or $30 \%$ decrease compared to the baseline), tachycardia (increase more than $20 \%$ compared to baseline or heart rate more than $120 / \mathrm{min}$ ), nausea/vomiting, and hypernatremia. If any of the aforesaid complications was seen, the rate of administration of vitamin $\mathrm{C}$ was decreased by $50 \%$ and if it continued, the infusion was stopped. Serum level of vitamin $C$ was noted at baseline and 48

hours after vitamin $\mathrm{C}$ administration. Duration of mechanical ventilation, ICU length of stay, $\mathrm{PaO}_{2} / \mathrm{FiO}_{2}$ and mortality rate were noted for all patients until the $28^{\text {th }}$ day.

Sample size was calculated based on the mortality rate in Marik et al. study ${ }^{13}$ and a test on comparison of proportions with a-error of $5 \%$ and power of $80 \%$. Twenty-five subjects per group was calculated and considering the loss to follow, the ICU patients' turn-over, and the number of patients admitted with the diagnosis of pneumonia during the same period in previous years, it was increased to 40 in each group. Data were analyzed using SPSS 17 software and reported as mean \pm standard deviation for the continuous variables, and percentage for discrete variables. Non continuous variables were analyzed with Chi-square and continuous variables were analyzed with T-test. Organ dysfunction indices based on SOFA/APACHE scores were compared by regression correlation and T-test. A P-value of less than 0.05 was considered significant.

\section{Results}

A total of 141 critically ill patients with severe pneumonia were eligible for this study. Fifty-eight patients were excluded from the study and 83 patients were randomized into two groups. Three patients were withdrawn due to mortality before 48 hours and patient refusal to participate in the study (Figure 1). Finally, two groups of 40 patients were analyzed in this randomized trial. Mean age of patients was $57.95 \pm 12.9$ years with the male/female ratio of $46 / 34$. Frequencies of hospital acquired pneumonia, community acquired pneumonia and ventilator associated pneumonia were 34,21 and 25, respectively. Demographic characteristics of patients during the study are shown in table 1. Vasopressor was used in 48 patients and the only used vasopressor was norepinephrine. Duration of mechanical ventilation and vasopressor use was significantly less in intervention group $(p<0.001$ and $=0.003$, respectively). Our results showed that SOFA score decreased during the study in both groups but the level of this reduction was more in intervention group than the control group. Moreover, its difference was significant at 72 and 96 hours between two groups ( $p=0.01$ and $<0.001$, respectively). The results were the same for procalcitonin, $\mathrm{C}$-reactive protein and $\mathrm{PaO}_{2} / \mathrm{FiO}_{2}$ levels in two groups after 24 hours. Baseline levels of vitamin $\mathrm{C}$ in both groups did not have significant difference but the level increased in intervention group 
and decreased in control group during the study (Table2). Totally, 17 patients died in this study which 6 of them were in intervention group. Results showed that mortality was insignificantly lower in intervention group ( $p=0.17)$. Three patients showed hypotension and tachycardia during the administration of vitamin $\mathrm{C}$ which was self-limited by decreasing the dose of vitamin $\mathrm{C}$. The frequency of acute kidney injury in two groups did not have a significant difference $(p=0.12)$

Table 1, Demographic characteristics of patients

\begin{tabular}{|l|c|c|c|}
\hline \multicolumn{1}{r|}{ Variable } & Control & Intervention & $P$ value \\
\hline Age (Years) & $58.25 \pm 13.1$ & $56.93 \pm 12.3$ & 0.47 \\
\hline Male/Female & $22 / 16$ & $24 / 18$ & 0.39 \\
\hline APACHE & $22.7 \pm 4.26$ & $24.5 \pm 5.35$ & 0.57 \\
\hline SOFA & $10.7 \pm 2.70$ & $12.54 \pm 2.65$ & $<0.001$ \\
\hline $\begin{array}{l}\text { Pneumonia } \\
\text { VAP }\end{array}$ & 12 & 13 & \\
CAP & 10 & 11 & 0.56 \\
HAP & 18 & 16 & \\
\hline PSI & $188.52 \pm 52 \pm 33.87$ & $194.72 \pm 29.83$ & 0.38 \\
\hline CURB-65 & $3.55 \pm 0.71$ & $3.72 \pm 0.67$ & 0.26 \\
\hline MV duration(day) & $8.92 \pm 2.96$ & $4.05 \pm 2.29$ & $<0.001$ \\
\hline ICU LOS(day) & $14.15 \pm 3.12$ & $12.77 \pm 3.71$ & 0.07 \\
\hline Vasopressor use(day) & $3.39 \pm 1,23$ & $2.28 \pm 1.24$ & 0.003 \\
\hline Vasopressor dose(microg/min) & $8.26 \pm 3.58$ & $6.8 \pm 3.18$ & 0.14 \\
\hline Need to mechanical ventilation & \\
\hline Mortality & 9 & 5 & 0.24 \\
\hline
\end{tabular}

APAHE: acute physiology and chronic health evaluation assessment pneumonia HAP: hospital acquired pneumonia HAP: hospital acquired pneumonia 90/60 $\mathrm{mm} \mathrm{Hg}$, age > 65) a: only for patients with HAP and CAP.

SOFA: sequential organ failure CAP: community acquired PSI: pulmonary severity index
ory rate $>30 /$ min, blood pressure $<$ $r e$

\section{$<$}

Table 2, clinical variables during treatment in two groups 


\begin{tabular}{|c|c|c|c|c|c|}
\hline Variable & T0 & $\mathrm{T} 24$ & T48 & T72 & T96 \\
\hline $\begin{array}{c}\text { SOFA } \\
\text { Intervention } \\
\text { Control } \\
P \text { value }\end{array}$ & $\begin{array}{c}12.45 \pm 2.65 \\
10.7 \pm 2.70 \\
<0.001\end{array}$ & $\begin{array}{c}10.27 \pm 2.60 \\
8.8 \pm 2.65 \\
0.01\end{array}$ & $\begin{array}{c}7.1 \pm 1.92 \\
7.92 \pm 2.81 \\
0.93\end{array}$ & $\begin{array}{c}3.72 \pm 1.75 \\
4.85 \pm 2.51 \\
0.01\end{array}$ & $\begin{array}{c}1.62 \pm 1.19 \\
3.10 \pm 1.61 \\
<0.001\end{array}$ \\
\hline $\begin{array}{c}\text { PCT } \\
\text { Intervention } \\
\text { Control } \\
P \text { value } \\
\end{array}$ & $\begin{array}{c}37.25 \pm 20.93 \\
45.28 \pm 28.60 \\
0.15\end{array}$ & $\begin{array}{c}26.50 \pm 15.30 \\
28.07 \pm 17.48 \\
0.67\end{array}$ & $\begin{array}{c}11.10 \pm 6.04 \\
16.27 \pm 11.71 \\
0.01\end{array}$ & $\begin{array}{l}4.02 \pm 2.34 \\
7.72 \pm 7.29 \\
<0.001\end{array}$ & $\begin{array}{c}1.36 \pm 0.79 \\
2.82 \pm 1.39 \\
<0.001\end{array}$ \\
\hline $\begin{array}{c}\text { CRP } \\
\text { Intervention } \\
\text { Control } \\
P \text { value }\end{array}$ & $\begin{array}{c}27.40 \pm 11.66 \\
24.27 \pm 12.83 \\
0.25\end{array}$ & $\begin{array}{c}36.60 \pm 13.85 \\
45.1 \pm 19.50 \\
0.02\end{array}$ & $\begin{array}{l}14.97 \pm 7.31 \\
24.32 \pm 12.72 \\
<0.001\end{array}$ & $\begin{array}{c}6.70 \pm 3.61 \\
11.47 \pm 7.51 \\
<0.001\end{array}$ & $\begin{array}{l}2.30 \pm 0.66 \\
4.79 \pm 1.78 \\
<0.001\end{array}$ \\
\hline $\begin{array}{c}\text { Pao2/Fio2 } \\
\text { Intervention } \\
\text { Control } \\
P \text { value } \\
\end{array}$ & $\begin{array}{c}126.42 \pm 27.60 \\
140.51 \pm 29.70 \\
0.99\end{array}$ & $\begin{array}{c}191.49 \pm 25.60 \\
178.21 \pm 26.61 \\
0.6\end{array}$ & $\begin{array}{c}224.62 \pm 23.40 \\
201.50 \pm 28.88 \\
<0.001\end{array}$ & $\begin{array}{c}262.87 \pm 30.59 \\
229.95 \pm 33.10 \\
<0.001\end{array}$ & $\begin{array}{c}292.65 \pm 29.42 \\
257.20 \pm 33.73 \\
<0.001\end{array}$ \\
\hline $\begin{array}{c}\text { Vitamin C } \\
\text { Intervention } \\
\text { Control } \\
P \text { value }\end{array}$ & $\begin{array}{c}20.63 \pm 12.74 \\
22.77 \pm 13.56 \\
0.47\end{array}$ & & & & $\begin{array}{c}79.20 \pm 26.42 \\
16.38 \pm 10.33 \\
<0.001\end{array}$ \\
\hline
\end{tabular}

SOFA: Sequential organ failure assessment

PCT: Procalcitonin

CRP: C reactive protein

\section{Discussion}

The main finding of this study is that administration of high dose intravenous vitamin $\mathrm{C}$ in critically ill patients with severe pneumonia is safe. This treatment is associated with decreasing in duration of mechanical ventilation and vasopressor usage and also improvement in oxygenation with concomitant decrease in pulmonary severity indices without any significant decrease in ICU length of stay and mortality.

Vitamin $\mathrm{C}$ is known to be used for treating of cancer and respiratory viral infections. However, new information regarding the pharmacokinetic properties of vitamin $\mathrm{C}$ and results of recent studies have raised interest in the utilization of high-dose vitamin $\mathrm{C}$ in critically ill patients ${ }^{14}$. Previous studies showed that treatment with vitamin $\mathrm{C}$ decreased procoagulant and proinflammatory markers in respiratory system which resulted in lower lung injury ${ }^{15}$.Vitamin $\mathrm{C}$ can also diminish the sequestration of neutrophils, improve alveolar fluid clearance, and maintain lung barrier function ${ }^{16}$. Moreover, vitamin $\mathrm{C}$ can counter oxidative stress by decreasing hydrogen peroxide, superoxide anion, and nitric oxide levels ${ }^{17}$. So, vitamin $\mathrm{C}$ not only increases bacterial killing potency in early stages but also modulates the immune response in later stages of disease. These evidences were supported by our results which showed that vitamin $\mathrm{C}$ administration significantly diminished the inflammatory and severity markers of critically ill patients ${ }^{18}$. Results of CITRISALI randomized clinical trial showed that, a 96-hour infusion of vitamin C compared with placebo in the patients with sepsis did not significantly improve organ dysfunction scores or alter markers of 
inflammation and vascular injury ${ }^{12}$. Our results showed a significant improvement in the SOFA score on 72 and 96 hours which may result from the deteriorated conditions of certain patients, leaving the survived patients with less severe conditions for statistical analysis at the primary end points. Now a randomized controlled trial to ascertain the effect of vitamin $\mathrm{C}$ on the composite endpoint of death or persistent organ dysfunction at 28 days in patients with sepsis is under investigation which can help to better defining of this problem ${ }^{19}$.

Results of an interesting study showed that nearly $70 \%$ of critically ill patients had hypovitaminosis C despite receiving standard ICU nutritional support which emphasized the importance of its substitution in critically ill patients ${ }^{2}$. Results of a recently performed RCT showed that administration of $15 \mathrm{~g} /$ day of intravenous vitamin C for 96 hours in 167 patients with ARDS due to sepsis showed a decrease in mortality ${ }^{12}$. This trial used the same duration but much higher doses of vitamin $\mathrm{C}$ compared to our trial with a larger sample size; this can explain its results regarding mortality. One important point regarding administration of vitamin $\mathrm{C}$ is the fact that it is not possible to restore normal levels with oral supplementation due to saturable absorption kinetics and reduced absorption in critical illness; so, intravenous administration is necessary. The other point is the time to start vitamin $C$ therapy. The earlier the treatment is started, the better are the results. Delayed starting in patients evolves into a phase of irreversible multi-system organ failure and at this time treatment may be futile. Hemila et al. in a recently published meta-analysis evaluated six trials of vitamin $\mathrm{C}$ administration in ICU. In three trials in which patients needed mechanical ventilation for over 24 hours, vitamin $\mathrm{C}$ shortened the duration of mechanical ventilation by $18.2 \%$ ( $95 \% \mathrm{Cl} 7.7 \%$ to $27 \% ; p=0.001)$. They recommended that the effect of vitamin $\mathrm{C}$ should be investigated in more trials based on low cost and decrement in ICU length of stay ${ }^{20}$. Cai et al. showed that vitamin $\mathrm{C}$ can improve the outcome in pneumonia due to influenza virus by its effect on inhibition of CORT synthesis which reduces the susceptibility to influenza viral infection ${ }^{21}$. Regarding critically ill COVID-19 patients with pneumonia with a high mortality rate, it seems that timely administration of high dose intravenous vitamin $C$ has been particularly effective by inhibiting the production of cytokine storm due to COVID-1922.

Results of this study showed that administration of intravenous vitamin $\mathrm{C}$ can increase concentration of vitamin $C$ in critically ill patients after 72 hours. We showed that the level of CRP, PCT, SOFA score and P/F ration was significantly improved after 72 hours. Combining the results, we can conclude that significant increase in levels of vitamin $\mathrm{C}$ can result in significant improvement in pulmonary organ function and decreasing in inflammation/ infection in critically ill patients which is similar to previous results.

The present study has several limitations. It was a single center design with relatively small sample size in a medical ICU. The resulting low power of study may have limited our ability to detect significant effects of the vitamin $\mathrm{C}$ protocol on the primary and secondary outcome variables. Previous studies regarding the effect of the vitamin $C$ in critically ill patients are mostly done in septic patients. There is few studies on the effect of vitamin $C$ on the pneumonia and because of the low number of trials, we first wanted to show the effect of administration of vitamin $C$ in patients with pneumonia, then evaluating the effect of vitamin $C$ on different subgroups of pneumonia. Thus, the results of this study cannot be generalized to all critically ill 
patients with pneumonia, different comorbidities or surgical problems. Also, 15 patients in control group and 10 patients in intervention group received corticosteroid for shock reversal, resulting in diminution in vasopressor dose which could interfere with our results.

\section{Conclusion}

Our results showed that the intravenous administration of a relative high dose of vitamin $\mathrm{C}$ to critically ill patients with severe pneumonia is safe and can decrease the inflammation, mechanical ventilation duration, and vasopressor use without any significant effect on mortality. However, based on the aforesaid limitation, future large randomized controlled studies are needed to evaluate the optimal dose and duration, and probable adverse effects of vitamin C in critically ill patients with severe pneumonia.

\section{Abbreviations}

CURB-65: Confusion, Uremia, Respiratory Rate, Blood Pressure And Age $\geq 65$ Years

PSI: Pneumonia Severity Index

ICU: Intensive Care Unit

SOFA: Sequential Organ Failure Assessment

APACHEIl: Acute Physiologic And Chronic Health Evaluation

\section{Declarations}

\section{Ethics approval:}

Data collection and analysis were determined by Tabriz University of Medical Sciences of IRAN, ISLAMIC REPUBLIC OF, to be part of the continual public health investigation and the informed consent form was taken from the patient or his / her legal guardian. the informed consent and ethics approval was approved by Regional Research Ethics Committee, Tabriz University of Medical Sciences, by Approval ID: IR.TBZMED.REC.1398.482 and Approval Date : 2019-07-29.

\section{Consent to publication:}

Not applicable

\section{Availability of data and materials:}

The datasets used and/or analyzed during the current study are available from the corresponding author on reasonable request

\section{Competing interests:}


All authors declare no conflict of interest

Funding:

This research received no external funding

Author information:

Affiliations

Faculty of Medicine, Tabriz University of Medical Sciences, Iran

Ata Mahmoodpoor, Kamran Shadvar,Seied Hadi Saghaleini

Neurosciences Research Institute, Aging Research Institute, Tabriz University of Medical Sciences,Iran

Sarvin Sanaie

Students Research Committee, Tabriz University of Medical Sciences, Iran

Mir Reza Hadipoor

Yeditepe Dental Student Association Research Committee Member, Faculty of Dentistry, Yeditepe University, Turkey

Mohammad Ata Pourmoghaddam

Corresponding author

Seied Hadi Saghaleini

Author Contributions:

For this RCT Ata M. and Kamran Sh. contributed in methodology, data curation ; Ata M. and Seied .H.S conceived and designed the study and contributed in writing and original draft preparation and supervision ;Sarvin S. and Mir R.H. analyzed the data and edited draft; Mohammad A.P. conferred for review and editing supervision. All authors have read and agreed to the published version of the manuscript.

Acknowledgments:

The authors wish to thank all subjects who participated in the study

\section{References}

1. Padayatty SJ, Levine M. Vitamin C: the known and the unknown and Goldilocks. Oral Dis. 2016; 22(6):463-93. 
2. Carr AC, Rosengrave PC, Bayer S, Chambers S, Mehrtens J, Shaw GM. Hypovitaminosis C and vitamin $\mathrm{C}$ defciency in critically ill patients despite recommended enteral and parenteral intakes. Crit Care. 2017;21(1):300

3. Marik P.E. Hydrocortisone, ascorbic acid and thiamine (HAT Therapy) for the treatment of sepsis. Focus on ascorbic acid. Nutrients. 2018; 10(11): 1762.

4. Fujii T, Luethi N, Young P.J, Frei D.R, Eastwood G.E, French C.J, et al. Effect of Vitamin C, Hydrocortisone, and Thiamine vs Hydrocortisone alone on time alive and free of vasopressor support among patients with Septic shock. The VITAMINS randomized clinical trial. JAMA; 2020; 323(5):423431.

5. Corkovic L, Begovic D, Milosevic D, Miloskovic V, Obradovic M, Jelic S, et al. serum vitamin C level in patients with acute pneumonia and in COPD patients before and after therapy. Chest 2006; 130: 184 s.

6. Hemila H. Vitamin $\mathrm{C}$ supplementation and respiratory infections: a systematic review. Military medicine 2004 169; 11: 920-25.

7. Padhani ZA, Moazzam Z, Ashraf A, Bilal H, Salam RA, Das JK, Bhutta ZA. Vitamin C supplementation for prevention and treatment of pneumonia. Cochrane Database of Systematic Reviews 2020, Issue 4. Art. No.: CD013134. DOI: 10.1002/ 14651858. CD013134.pub2.

8. Levine M, Rumsey SC, Daruwala R, Park JB, Wang Y. Criteria and recommendations for vitamin C intake. JAMA. 1999; 281(15):1415-23.

9. Long CL, Maull KI, Krishnan RS, Laws HL, Geiger JW, Borghesi L, et al. Ascorbic acid dynamics in the seriously ill and injured. J Surg Res. 2003; 109(2):144-8.

10. de Grooth HJ, Manubulu-Choo WP, Zandvliet AS, Spoelstra-de Man AME, Girbes AR, et al. Vitamin c pharmacokinetics in critically III patients: a randomized trial of four IV regimens. Chest. 2018; 153(6):1368-77.

11. Zabet MH, Mohammadi M, Ramezani M, Khalili H. Efect of high-dose ascorbic acid on vasopressor's requirement in septic shock. J Res Pharm Pract. 2016; 5(2):94-100.

12. Fowler AA 3rd, Truwit JD, Hite RD, Morris PE, DeWilde C, Priday A, et al. Efect of vitamin $C$ infusion on organ failure and biomarkers of infammation and vascular injury in patients with sepsis and severe acute respiratory failure. JAMA. 2019; 322(13):1261-1270. doi:10.1001/jama.2019.11825

13. Marik PE, Khangoora V, Rivera R, Hooper MH, Catravas J. Hydrocortisone, Vitamin C, and Thiamine for the Treatment of Severe Sepsis and Septic Shock: A Retrospective Before-After Study. Chest 2017; 151(6): 1229-38.

14. Boretti A, Banik B.K. Intravenous vitamin C for reduction of cytokines storm in acute respiratory distress syndrome. Pharma Nutrition. 2020 Jun; 12: 100190

15. Fisher BJ, Seropian IM, Kraskauskas D, Thakkar JN, Voelkel NF, Fowler 3rd AA, et al. Ascorbic acid attenuates lipopolysaccharide-induced acute lung injury. Crit Care Med 2011; 39:1454-60.

16. Fisher BJ, Kraskauskas D, Martin EJ, Farkas D, Wegelin JA, Brophy D, et al. Mechanisms of attenuation of abdominal sepsis induced acute lung injury by ascorbic acid. Am J Physiol Lung Cell Mol Physiol 2012; 303: L20-32. 
17. Lobo V, Patil A, Phatak A, Chandra N. Free radicals, antioxidants and functional foods: impact on human health. Pharmacogn Rev 2010; 4: 118-26.

18. Hamishehkar, H., Beigmohammadi, M. T., Abdollahi, M., Ahmadi, A., Mahmoodpour, A., Mirjalili, M. R., et al. Identification of enhanced cytokine generation following sepsis. Dream of magic bullet for mortality prediction and therapeutic evaluation. Daru 2207; 18(3), 155-162.

19. Masse M.H, Menard J, Sprague Sh, Battista M.C, J.CooK D, H Guyyatt G, et al. Lessening Organ dysfunction with VIT amine C (LOVIT): protocol for a randomized controlled trial. Trials 2020; 21: 42.

20. Hemila $\mathrm{H}$, Chalker E. Vitamin $\mathrm{C}$ can shorten the length of stay in the ICU: A meta analysis. Nutrients 2019; 11(4): 708; doi:10.3390/nu11040708

21. Cai Y, Li Y, Tang L, Tsci B, Chen M, Chen $H$, et al. A new mechanism of vitamin $C$ effects on A/FM/1/47(H1N1) Virus-Induced Pneumonia in Restraint-Stressed Mice. Biomed Res Int. 2015; 2015: 675149

22. Erol A. OSF Preprints; 2020. High-dose Intravenous Vitamin C Treatment for COVID-19.

\section{Figures}




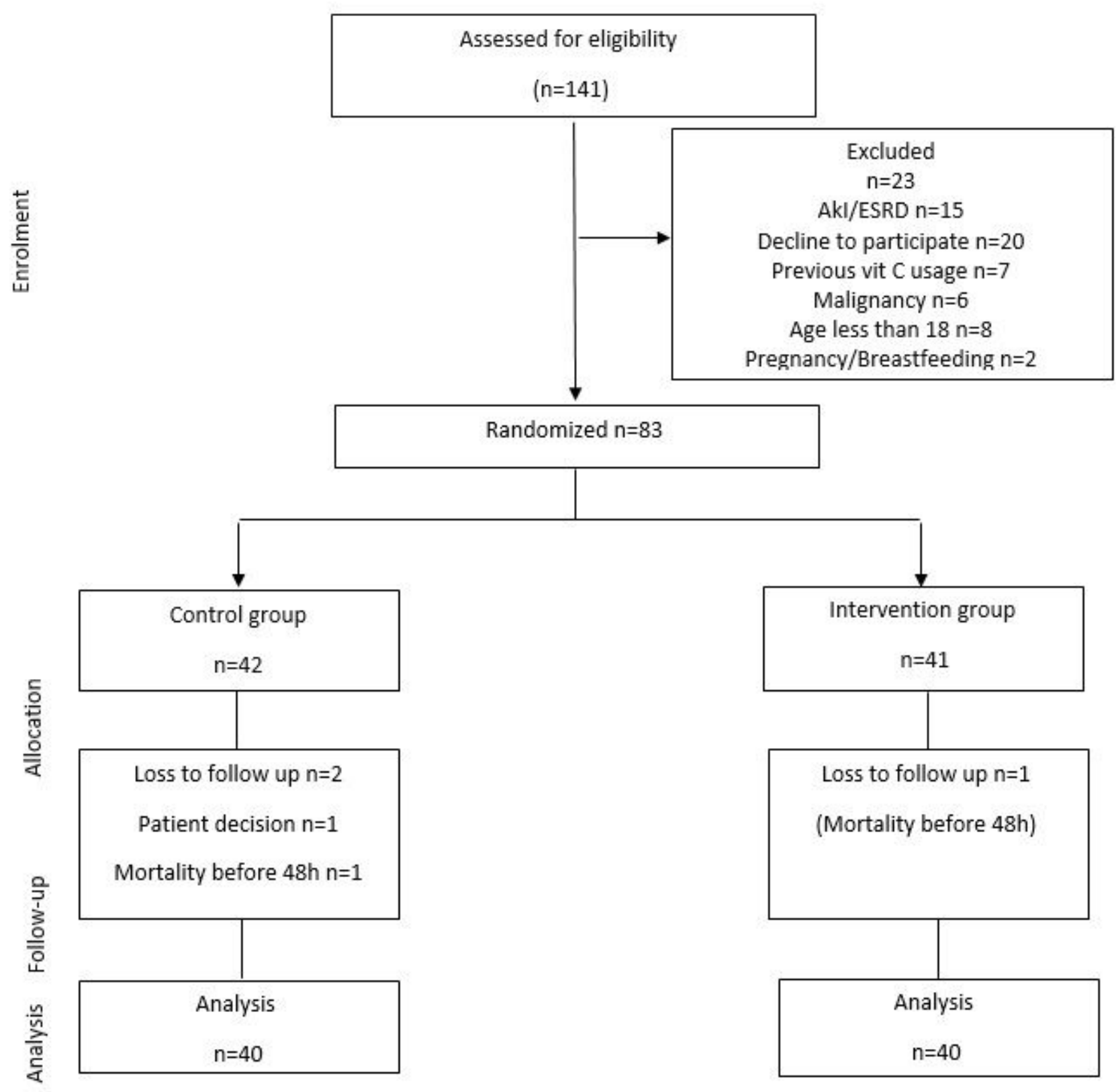

\section{Figure 1}

Flow diagram of the study

\section{Supplementary Files}

This is a list of supplementary files associated with this preprint. Click to download.

- CONSORT2010Checklistforvitc.doc 